\title{
MAPEAMENTO GEOLÓGICO DA REGIÃO DE GOUVEIA / MG COM AUXÍLIO DE MÉTODOS GEOFÍSICOS
}

\author{
Paulo Roberto Antunes Aranha ${ }^{1}$, Rodrigo Macedo Pena ${ }^{2}$, Luiz Guilherme Knauer ${ }^{3}$
}

\section{RESUMO}

\begin{abstract}
Na região da cidade de Gouveia, Serra do Espinhaço, Minas Gerais, devido a escassez de afloramentos, foram utilizados métodos geofísicos de cintilometria e Georadar buscando-se desenvolver um critério geofísico na individualização das litologias não-aflorantes presentes na área, mesmo com a presença de milonitos e forte intemperismo. Os dados geofísicos foram analisados separadamente para cada perfil obtido, e um valor em torno de 185 CPS (cintilações por segundo) para rochas do Complexo de Gouveia indeformado e 80 CPS para rochas da Formação Barão de Guaicuí pôde ser considerado como guia prospectivo. Ademais, as imagens da subsuperfície puderam mostrar estruturas: falhas, fraturas, presença de colúvios, etc. Nesta área foram identificadas quatro unidades lito-estratigráficas principais: (a) Complexo de Gouveia, representado por granitos s.l; (b) Formação Barão do Guaicuí, representado por quartzo-sericita-xisto típico; (c) Formação Galho do Miguel, representado por espessos pacotes homogêneos de quartzito esbranquiçado puro e fino, e (d) rocha metabásica representada por rochas máficas e maciças de coloração levemente esverdeadas. Destaca-se uma foliação milonítica principal, $\mathrm{S}_{1}$, de atitude dominante $095-085 / 40$ e falhamentos regionais de orientação geral NW/SE. Nos xistos e granitos esta foliação rotaciona e deforma grãos, podendo aparecer todos os termos miloníticos.
\end{abstract}

\begin{abstract}
The Gouveia region, Espinhaço Ridge, Minas Gerais State, is marked by the lack of outcrops, geophysics cintilometry and Ground Penetrating Radar methods were used in order to attach a litostratigraphic individualization criteria, even with strong milonitization and laterization. These geophysical data was individually analyzed and a value of 185 CPS for indeformed Gouveia Complex and 80 CPS for Barão do Guaiuí Formation could be taken as prospect guidance. The radargrams were useful to realize the subsurface structure, faults, fractures, and coluvium. In this area four main litostratigraphic units was identified: (a) Gouveia Complex, represented by s.l granites (b) Barão do Guaicuí Formation, formed by typical quartzsericite-schist (c) Galho do Miguel Formation, represented by a thick, white and homogenous layer of quartzite and (d) Basic Igneous rocks, composed by mafic and massive, lightly greenly. A main milonitic foliation occurs, $\mathrm{S}_{1}$, dipping 095-085/40 as well as regional NW / SE fractures. In the schist and granite, that foliation causes rotation and deformation of some minerals. Milonitic rocks can also be found.
\end{abstract}

Keywords: georadar, gamma survey, geologic map

\section{INTRODUÇ̃̃O}

Este trabalho apresenta a utilização de métodos geofísicos para a caracterização de litologias, definição de contatos geológicos e estruturas, auxiliando a realização de mapeamento geológico de semi-detalhe, escala 1:25.000, na região de Gouveia/MG, na articulação das Quadrículas Onça e Cuiabá.

A área de estudo, englobada pelos meridianos $43^{\circ} 45^{\prime} 37,20^{\prime \prime}$ e $43^{\circ} 48^{\prime} 25,05^{\prime \prime} \mathrm{W}$ e os paralelos $18^{\circ} 27^{\prime} 12,18^{\prime \prime}$ "e $18^{\circ} 25^{\prime} 17,10^{\prime \prime}$ 'S encontra-se na figura 1 .

A rede de drenagem pertence integralmente à Bacia Hidrográfica do Rio São Francisco, dividindo-se em uma sub-bacia denominada Sub-Bacia do Rio Paraúna (Rio afluente de segunda ordem do São Francisco). Localmente, pode-se dividir a área mapeada em outra sub-bacia, a do Ribeirão do Chiqueiro. Esta, a mais importante da região de Gouveia, abrange toda a área de estudo, com o Ribeirão homônimo descrevendo um traçado geral de norte para sul. Os principais afluentes localizam-se na margem direita (Córrego do Bicho,
Córrego Rio Grande, Lapinha e das Almas). Estes exibem um padrão geral dendrítico a sub-dendrítico e cursos com orientação dominante NW / SE coincidente com os lineamentos estruturais (Pena 2006).

A sub-bacia do Ribeirão do Chiqueiro, que compõe o alto curso da sub-Bacia do Rio Paraúna, apresenta-se como uma bacia de curso regularizado suspensa sobre a depressão ocupada pelas rochas do Supergrupo Rio Paraúna e a seqüência infracrustal. Ele drena a semijanela estrutural de Gouveia, onde afloram as rochas e seqüências mais antigas dominadas por granitos e xistos, mais susceptíveis, portanto, ao intemperismo de clima tropical. A complexidade exaltada nas descrições dos cursos da sub-bacia do Ribeirão do Chiqueiro é determinada por diferentes fatores: litologias variadas (granitos, xistos, quartzitos e metabásicas); variações dinâmicas do relevo ao longo da sua elaboração e variações espaciais na sua configuração atual; diferentes padrões estruturais das litologias e nos conjuntos geotectônicos menores (Almeida-Abreu 1989). Sendo assim, pode-se entender porque dominam os cursos

1 - Departamento de Geologia - IGC/UFMG

2 - Graduação em Geologia - IGC/UFMG 3 - CPMTC - IGC/UFMG 


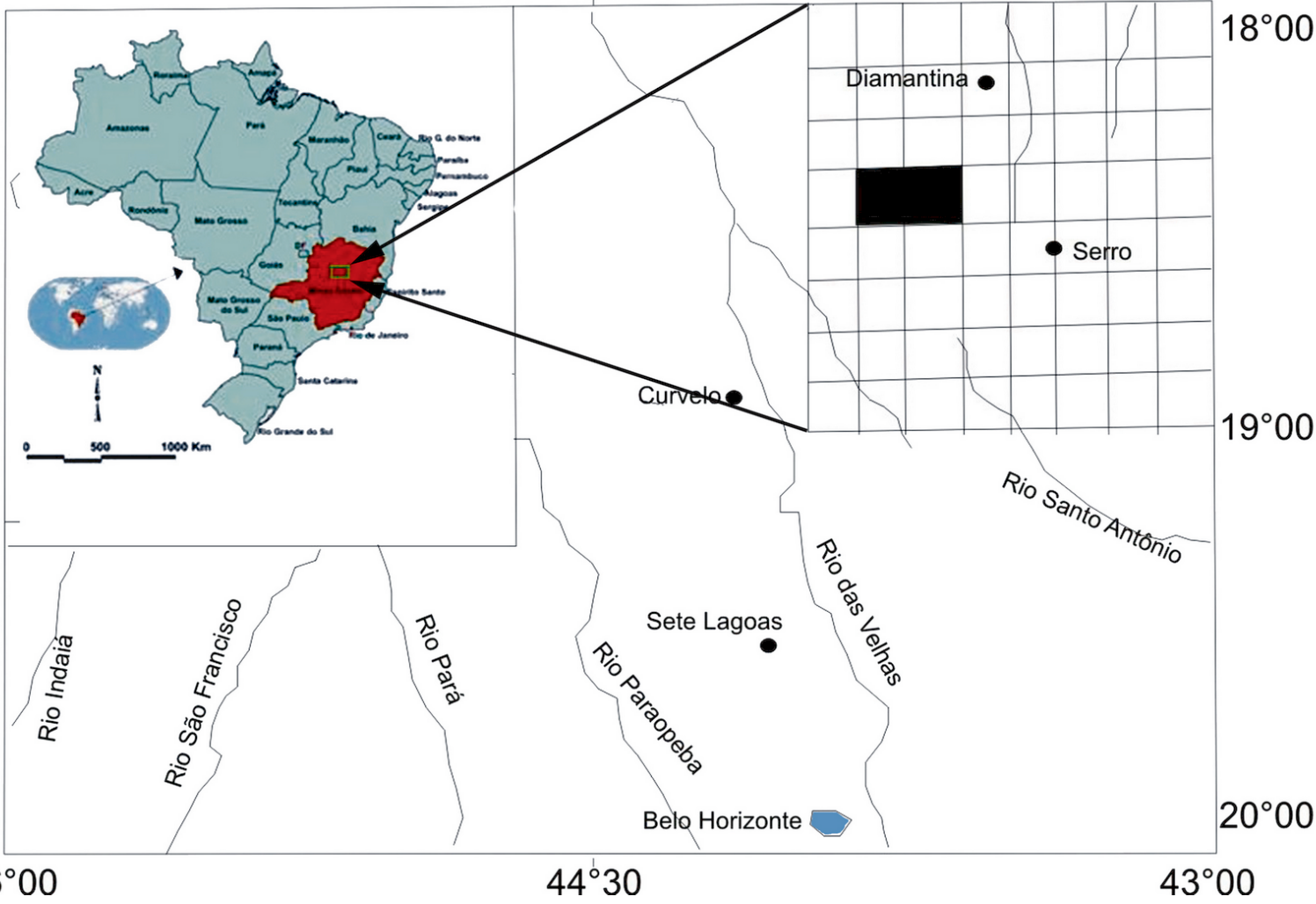

Figura 1 - Mapa de localização e acesso à região de Gouveia/MG.

adaptados aos lineamentos tectônicos.

Nos locais onde os afloramentos são escassos foram utilizados métodos geofísicos para auxiliar na interpetação geológica. Os métodos escolhidos foram Georadar e Cintilometria.

O Georadar utilizado para caracterizar, com grande resolução, as propriedades das rochas e estruturas a pequenas profundidades. Um grande número de trabalhos utilizando o método de Georadar foi publicado nas mais diversas áreas, especialmente naquelas ligadas à exploração mineral: Botelho et al. 1999; Souza Jr. \& Porsani 2001; geologia básica, Porsani \& Rodrigues 1995; Rodrigues \& Porsani 1997; hidrogeologia (Harari 1996) e geotecnia (Davis \& Annan 1988; Aranha et al. 1998; Aranha et al. 2002).

O método radiométrico consiste no fato de que os elementos radioativos naturais são encontrados em minerais e a determinação destes e de seus teores podem fornecer dados adicionais sobre as características das rochas. Em particular, $\mathrm{K}^{40}, \mathrm{Th}^{232}$ e $\mathrm{U}^{223}$ desempenham um papel predominante no estudo da radioatividade, devido à abundância inicial destes elementos. A radiometria pode ser simplificadamente definida como a medição da distribuição do material radioativo na superfície terrestre. Como a ocorrência dos elementos radioativos está intimamente correlacionada à composição mineralógica das rochas, litotipos podem apresentar uma radioatividade natural mais elevada que outros. Assim os dados referentes à radioatividade natural das rochas, medida na superfície do terreno, pode ser utilizada para a identificação de litotipos e seus contatos em superfície (Cordeiro et al. 2007; Carrino et al. 2007, Ruy et al. 2006). Existem duas formas específicas de levantamento de dados radiométricos de fótons gamma: cintilometria e espectometria. A cintilometria se baseia na medida da radiação total emitida pela rocha, enquanto a espectometria separa e mede a radiação proveniente de cada um dos elementos, $\mathrm{U}$, Th e K (e sua série de decaimento). Os levantamentos se dividem em aéreo e terrestre.

\section{GEOLOGIA REGIONAL}

A área de estudo localiza-se na porção centro-leste do Estado de Minas Gerais, região denominada Serra do Espinhaço Meridional, e inserida na Faixa Araçuaí (faixa esta que delimita o Cráton São Francisco a leste). O Espinhaço estende-se por cerca de $300 \mathrm{~km}$ na direção N-S partindo do Quadrilátero Ferrífero até a região de Olhos D'água (Almeida-Abreu 1995).

A geologia da Serra do Espinhaço é complexa, quase sempre de difícil interpretação. A litoestratigrafia da serra sempre foi alvo de grandes controvérsias no meio científico, em razão da idade avançada de suas formações e dos grandes esforços tectônicos aos quais elas foram submetidas (Almeida-Abreu 1995, Dossin \& Dussin 1995; Uhlein 1991).

Três conjuntos litoestratigráficos são tidos como principais na região: complexo granitognaisse-migmatítico basal (Complexo de Gouveia); 
seqüência metavulcano-sedimentar pré-Espinhaço (Supergrupo Rio Paraúna) e seqüência metassedimentar correspondente ao Supergrupo Espinhaço. Além disso, diques e sills metabásicos truncam as unidades supracitadas. Afloram ainda, particularmente na borda oeste da serra, litologias pertencentes ao Supergrupo São Francisco (Grupos Macaúbas e Bambuí).

Cavalgamentos são a tônica geral do(s) processo(s) deformacional(is), respondendo a uma compressão de leste para oeste. Uhlein et al. (1986) caracterizam dois domínios principais de deformação segundo o modelo de um único evento: a leste da Serra, desenvolve-se a tectônica de cavalgamentos vergentes à oeste com maior grau de deformação. O domínio ocidental, por sua vez, apresenta menor grau de deformação, disseminando-se dobras amplas e assimétricas com vergência para oeste.

\section{GEOLOGIA LOCAL}

Individualizam-se três unidades estratigráficas diferentes, sendo, destas, o Complexo de Gouveia e o Grupo Costa Sena (representado, aqui, pela Formação Barão de Guaicuí) dominantes na área. Destaca-se também a presença marcante, embora restrita, da Formação Galho do Miguel pertencente ao Supergrupo Espinhaço. A ocorrência litológica completa-se pela presença de rochas metabásicas, predominantemente sob a forma de diques e sills que cortam todas as litologias.

\section{Complexo Gouveia}

Recobre aproximadamente 35\% da área mapeada, dominando essencialmente todos os afloramentos nas regiões próximas aos vales dos ribeirões do Chiqueiro e Córrego Grande (as drenagens mais expressivas da região) e aqueles nos arredores da cidade de Gouveia. Ocorrências são comuns quando se caminha mais à oeste, afastando-se do núcleo da cidade. Neste caso, destacam-se os afloramentos na encosta leste da Serra do Engenho.

Expressa, geralmente, um relevo particularmente diferenciado daqueles formados sobre as outras ocorrências litológicas, destacando-se colinas dômicas e convexas. Freqüentemente, os afloramentos são formados por rochas fortemente intemperisadas, em alguns casos contendo grandes quantidades de caulim e um espesso manto de alteração. O número de afloramentos, principalmente fora do núcleo da cidade de Gouveia, é bem restrito.

\section{Grupo Costa Sena (Formação Barão de Guaicuí)}

Constitui uma faixa de afloramentos que recobre aproximadamente $40 \%$ da área de trabalho, de direção geral N-S na encosta E da Serra do Engenho, extremo oeste da área mapeada e área expressiva a Norte da saída de Gouveia para Diamantina; bem como afloramentos dispersos na região central da porção estudada. Geralmente, os afloramentos representados por esta unidade constituem morros "ásperos", com as constituições rochosas "alfinetando" as cristas. Todavia, afloramentos em terrenos arrasados, com as mais diversas "texturas", também são encontrados, particularmente em locais onde se formam espessos mantos de solo e o intemperismo é mais elevado. No tocante a quantidade de afloramentos, deve-se ressaltar que, assim como o Complexo de Gouveia, a Formação Barão de Guaicuí aflora pouco na área mapeada, salvo nas regiões acidentadas da encosta oeste da Serra do Engenho.

\section{METODOLOGIA}

Para a realização do mapeamento geológico foram utilizadas fotos aéreas na escala 1:25.000 (Fotos faixa 12 : $\mathrm{N}^{\circ} 829-25,830-25,831-25,832-25$ e faixa $13: \mathrm{N}^{\circ}$ $805-25,806-25,807-25$ e 808-25). Primeiramente, foram efetuados levantamentos geológicos de campo, com a realização de perfis e descrição de afloramentos espalhados pela área mapeada. Amostras dos diversos litotipos foram coletadas, visando a descrição microscópica destes bem como uma comparação mineralógica e textural quanto à diferentes áreas de ocorrência (Pena 2006). Tendo em vista que em muitos lugares não havia afloramento utilizou-se de métodos geofísicos para auxiliar a elaboração do mapa geológico, bem como resolver alguns problemas intrínsecos à área. Alguns perfis geofísicos foram efetuados em diversos locais considerados "problemáticos" do ponto de vista geológico. Os métodos utilizados em questão foram o Georadar e a Cintilometria.

O objetivo da realização de diversos perfis de Georadar e Cintilometria foi verificar a existência de descontinuidades estruturais, contatos litológicos bem como a caracterização do material não-aflorante em diversos pontos considerados como de difícil resolução.

A campanha geofísica constituiu-se de 04 perfis de Georadar, 14 perfis de Cintilometria, todos eles espalhados pela área mapeada e distribuídos em locais-chave para a conclusão e elaboração do mapa geológico (Pena 2006). Os dados geofísicos também foram processados convenientemente para permitir a interpretação dos perfis e/ou imagens.

A cintilometria, método utilizado neste trabalho, baseia-se na propriedade que certos meios possuem de emitirem luz quando excitados por radiação. A interação da radiação com o detector é, então, caracterizada por flashes de luz (cintilações), detectadas por válvulas fotomultiplicadoras. Essas válvulas fotomultiplicadoras inicialmente convertem as cintilações em fotoelétrons, através de emissão fotoelétrica (no fotocatodo) e, em seguida, ampliam a corrente de fotoelétrons em um processo de multiplicação por emissão secundária, através de uma série de diodos convenientemente dispostos. Cria-se, então, uma corrente elétrica que é registrada. Esta corrente é proporcional ao número de cintilações emitidas pelo material devido à sua interação 
com a radiação gamma.

Para o levantamento dos dados utilizou-se o cintilômetro de modelo SC-132, da empresa Mount Sopris Instrument Co. A obtenção desses dados ocorreu de maneira simples: os locais para a execução dos perfis foram selecionados, a linha de aquisição foi dividida em leituras em intervalos regulares cujas distâncias foram de $2 \mathrm{~m}$ e $5 \mathrm{~m}$, dependendo do detalhe requerido no local. Em cada ponto de aquisição o cintilômetro foi posicionado à mesma altura do solo $=0,80 \mathrm{~m}$, e a medida cps realizada e anotada, bem como a distância na qual a medida foi obtida. O posicionamento do cintilômetro a $0,80 \mathrm{~m}$ do solo é a altura do instrumento sendo erguido pelo operador com o braço pendente ao lado do corpo. O mesmo operador adquiriu todos os dados. A distância entre as estações foi estabelecida com auxílio de uma trena de $100 \mathrm{~m}$ que foi posicionada no solo ao longo do perfil a ser realizado. As coordenadas UTM dos pontos iniciais e finais de cada perfil foi obtido com auxílio de GPS de precisão.

Com os dados obtidos foram gerados perfis os quais foram interpretados baseando-se na variação da medida de $C P S$ - cintilações por segundo.

O outro método geofísico utilizado foi o Georadar, o qual emprega ondas de rádio com freqüências muito altas (normalmente entre $10-3.000 \mathrm{MHz}$ ). O principio físico e a metodologia de aquisição dos dados de Georadar é semelhante à técnica de reflexão sísmica. Difere-se, no caso, pela onda empregada, uma vez que a sísmica utiliza ondas elásticas e acústicas, enquanto o método Georadar utiliza ondas eletromagnéticas (EM).

O método consiste na transmissão de ondas EM repetidamente irradiadas para a subsuperfície através de uma antena transmissora colocada na superfície. $\mathrm{O}$ contraste entre as constantes dielétricas dos meios no qual a onda EM se propaga faz com que parte do sinal enviado pela antena transmissora seja refletido. As ondas refletidas são captadas por outra antena, receptora, também posicionada na superfície. A energia refletida é registrada em função do tempo de chegada da onda na superfície após incidir numa superfície refletora, sendo então amplificada, digitalizada e gravada. Após o processamento dos dados, o produto final consiste em uma imagem de alta resolução da subsuperfície. $\mathrm{O}$ equipamento utilizado no presente trabalho foi o RAMAC, fabricado pela Mala Geoscience.

O levantamento foi executado com antenas a distância constante (common offset), no qual o sistema é transportado ao longo de uma direção obtendo-se um perfil de reflexão: tempo versus posição. Os perfis foram realizados no modo descontínuo, no qual os dados são adquiridos em posições individuais, ficando o conjunto de antenas (transmissora e receptora) estacionadas momentaneamente em cada ponto de aquisição das medidas durante a emissão da onda.

Os parâmetros para aquisição de cada linha de Georadar foram: antena de $100 \mathrm{MHz}$, espaçamento entre pontos de aquisição: $0,2 \mathrm{~m}$; freqüência de amostragem: $1.090 \mathrm{MHz}$; espaçamento entre as antenas: 1,0m; posição das antenas: perpendicular à direção de aquisição do perfil.

\section{Resultados obtidos}

A partir da descrição e interpretação dos dados geológicos elaborou-se o mapa geológico da região (Figura 2). No entanto, houve situações em que não havia afloramento para visualização direta da rocha e/ou do contato entre dois litotipos, principalmente entre o embasamento (granito) e o xisto. A obtenção dos perfis relaciona-se à necessidade de caracterização desse contato geológico local entre o granito e o xisto,

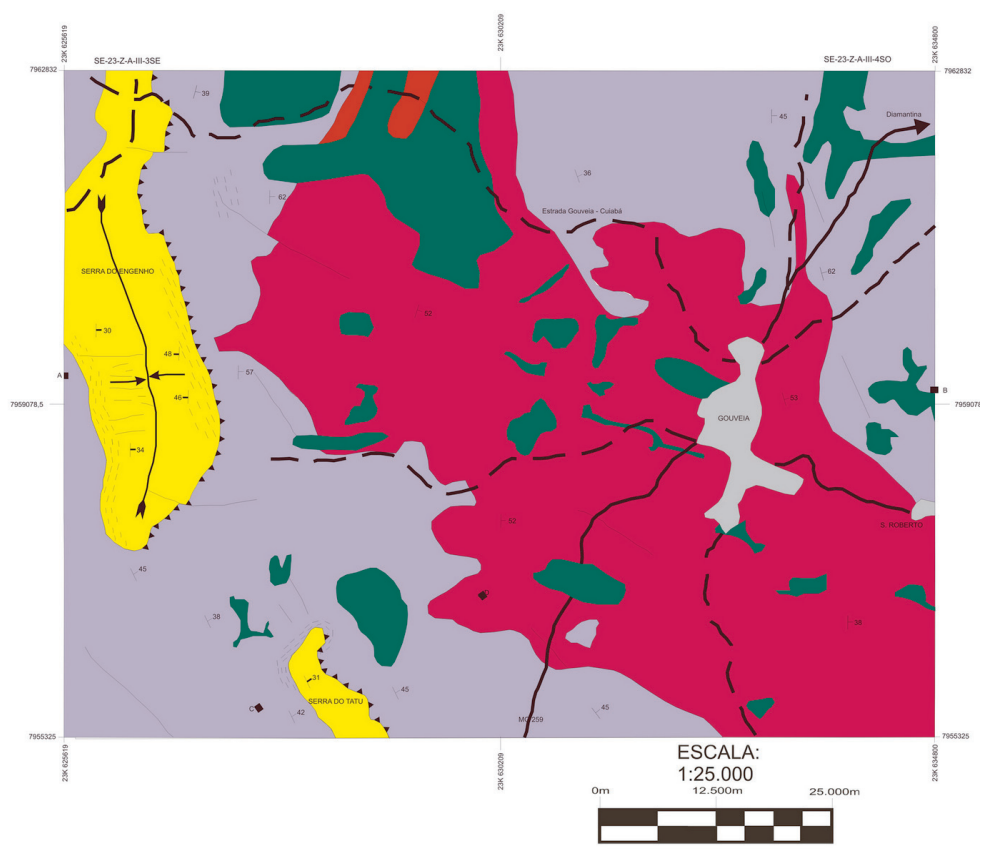

Figura 2 - Mapa geológico da região de Gouveia (modificado de Pena, 2006) 
uma vez que este não pôde ser feito através da descrição direta de afloramentos em campo.

Para caracterização do sinal geofísico de cintilometria associado ao embasamento e ao xisto, foram efetuados dois perfis-Base em locais de afloramento (com ausência de manto intempérico e solo residual) típico da rocha do embasamento (Complexo Gouveia) e do xisto (Figuras 3a; 3b). Os dados associados a estes perfis foram considerados como base de comparação para o restante das aquisições na área.

O perfil base de cintilometria obtido na área da figura 3a, sobre o embasamento (Figura 4a) mostra que, em geral, a resposta associada ao embasamento oscila em torno de 185 cintilações por segundo (CPS).
Notam-se pequenas variações sobretudo em locais de maior fraturamento/cisalhamento. Nesse caso a resposta cintilométrica pode chegar a valores próximos a 200 CPS, como observado no perfil na distância de $15 \mathrm{~m}$.

Para o perfil base de cintilometria sobre o xisto (Figura 3b) os valores obtidos são sempre menores quando comparados àqueles obtidos na área do embasamento. Os dados cintilométricos oscilam em torno de 80 CPS (Figura 4b). Nota-se um aumento nos valores da radioatividade na distância de $45 \mathrm{~m}$, fato este relacionado ao enriquecimento local devido a presença de um falhamento no final do perfil (Figura 3b).

Tendo com base estes resultados, buscou-se utilizálos sempre que havia na área dúvidas sobre a localização
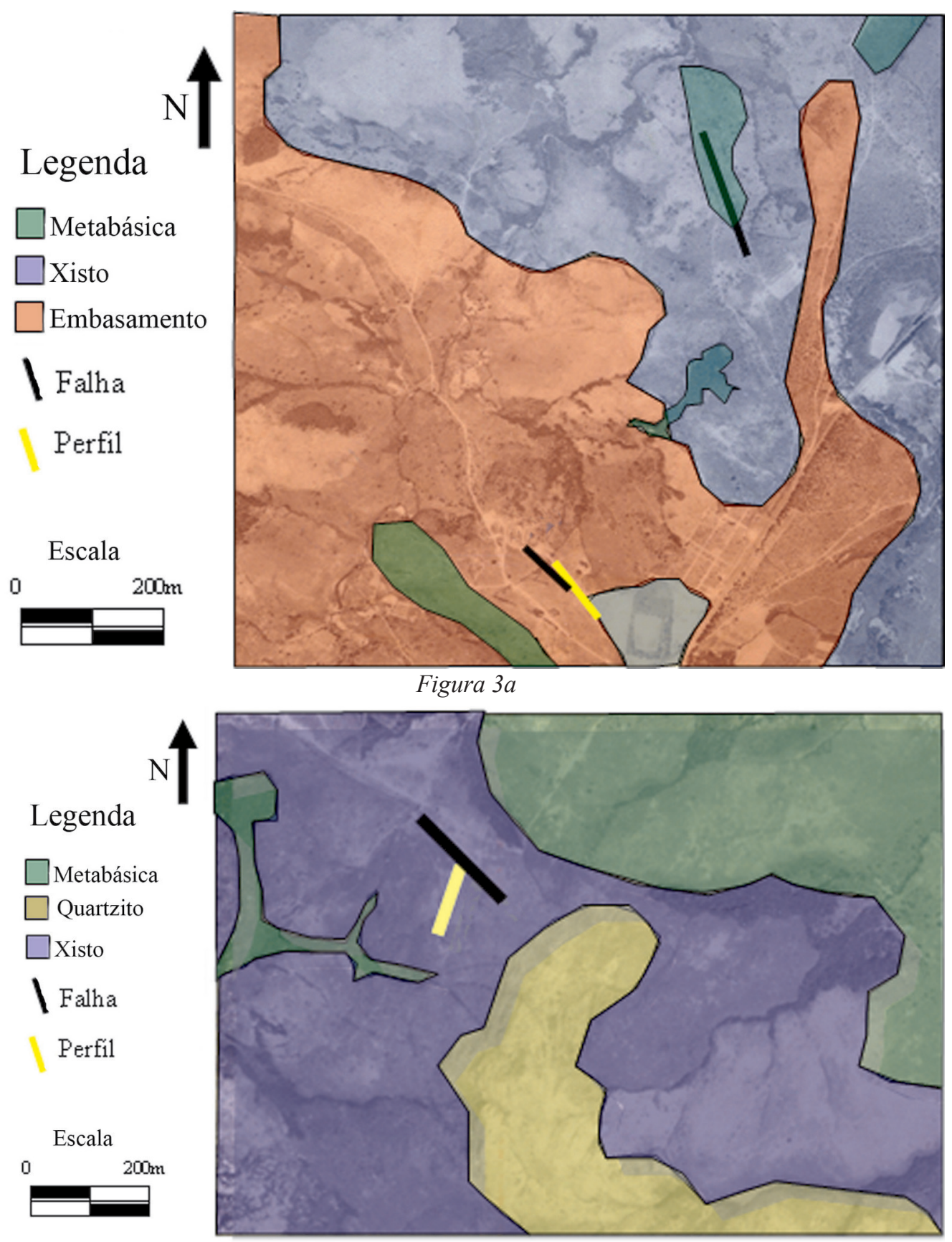

Figura $3 b$

Figuras $3 a$ e $3 b$ - Foto-aérea com interpretação geológica e com as localizações dos perfis bases de cintilometria: a) sobre o embasamento (granito); b) sobre o xisto. 
a)
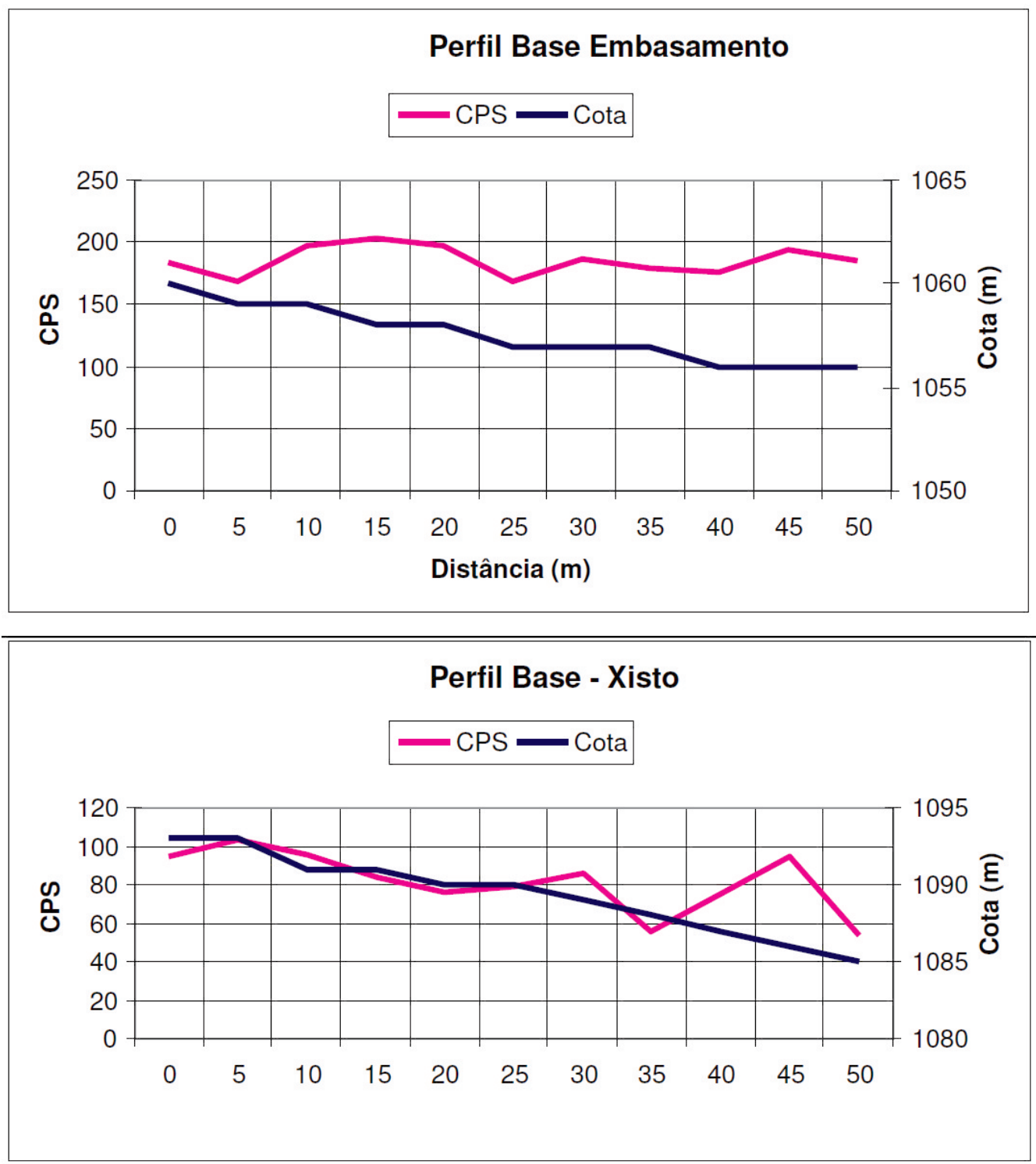

Figura 4 - a) Perfil base de cintilometria sobre o embasamento; b) Perfil base de cintilometria sobre o xisto.

real dos contatos pela falta de afloramento, ou pela presença de colúvio que impedia a correta interpretação da área.

$\mathrm{Na}$ área mostrada na figura 5 por se tratar de uma área cujas características de deformação e cisalhamento impostas aos tipos litológicos relacionados (o local apresenta um afloramento de granito milonitizado, Pena 2006), demandou também a caracterização da resposta geofísica neste caso particular. Para tanto, foram efetuados dois perfis cintilométricos paralelos entre si (Perfil 3 e 4). Os Perfis localizam-se em uma estrada de terra rumo a Norte dentro do bairro que está sendo construído à esquerda da entrada da cidade de Gouveia, sentido Diamantina (Figura 5).

Para obter um melhor detalhamento da seção, utilizou-se espaçamento de 2 metros entre cada medida, com obtenção das coordenadas UTM e cota da linha de aquisição a cada $10 \mathrm{~m}$ através de GPS (o intervalo de coordenadas e cota entre as medidas no GPS foi por interpolação linear simples).
Nos gráficos obtidos dos perfis 3 e 4 (Figuras 6a, 6b) notam-se claramente, a distinção de dois domínios principais: um sinal claramente representado por valores em torno de 160 CPS (figura 6a) e 170 CPS (Figura 6b). Neles observa-se uma transição para valores mais baixos, em torno de 78 CPS (Figura 6a) e 80 CPS (Figura 6b). Esta transição ocorre aproximadamente na distância de 52 metros do início do perfil, relaciona-se ao contato entre o granito e o xisto, considerando os dados cintilométricos dos Perfis base como parâmetros.

Os perfis de cintilometria mostram claramente a distinção entre o embasamento e o xisto, diferenciando um patamar com valores sempre superiores a 150 CPS e outro com valores próximos a $75 \mathrm{CPS}$.

Pode-se inferir que o contato entre estas litologias não é dotado de intensa remobilização fluida, apesar do tectonismo e cisalhamento associado. Para tanto, esperavam-se valores de CPS (principalmente) mais altos, relacionados a zonas de intenso cisalhamento.

Outra área escolhida ocorreu, principalmente, 


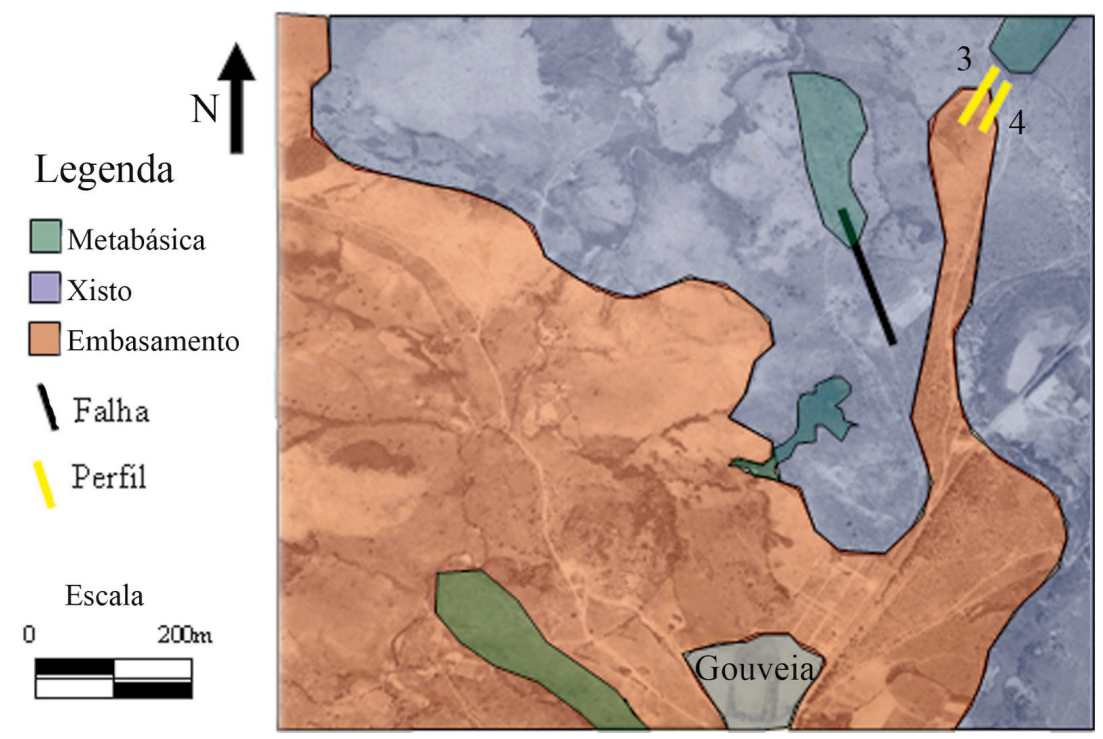

Figura 5 - Interpretação geológica da foto-aérea, com a localização dos perfis geofísicos 3 e 4, região de Gouveia, $M G$.

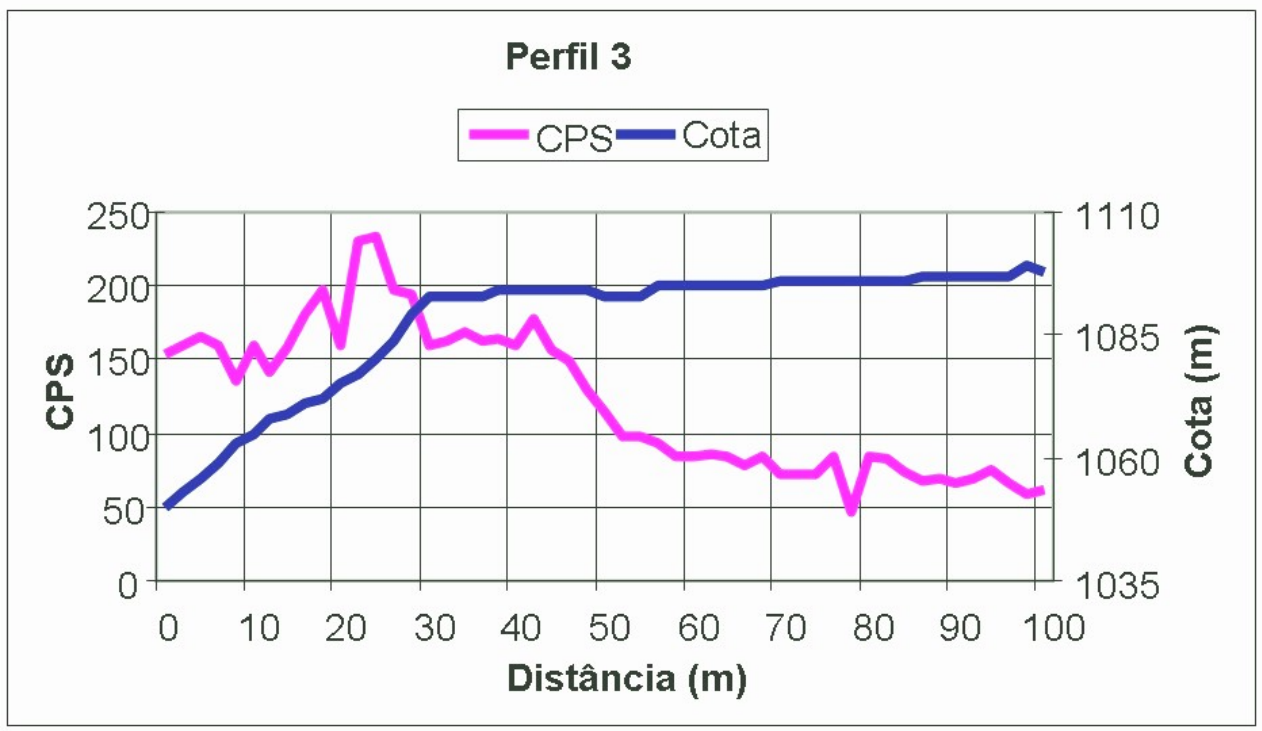

a)

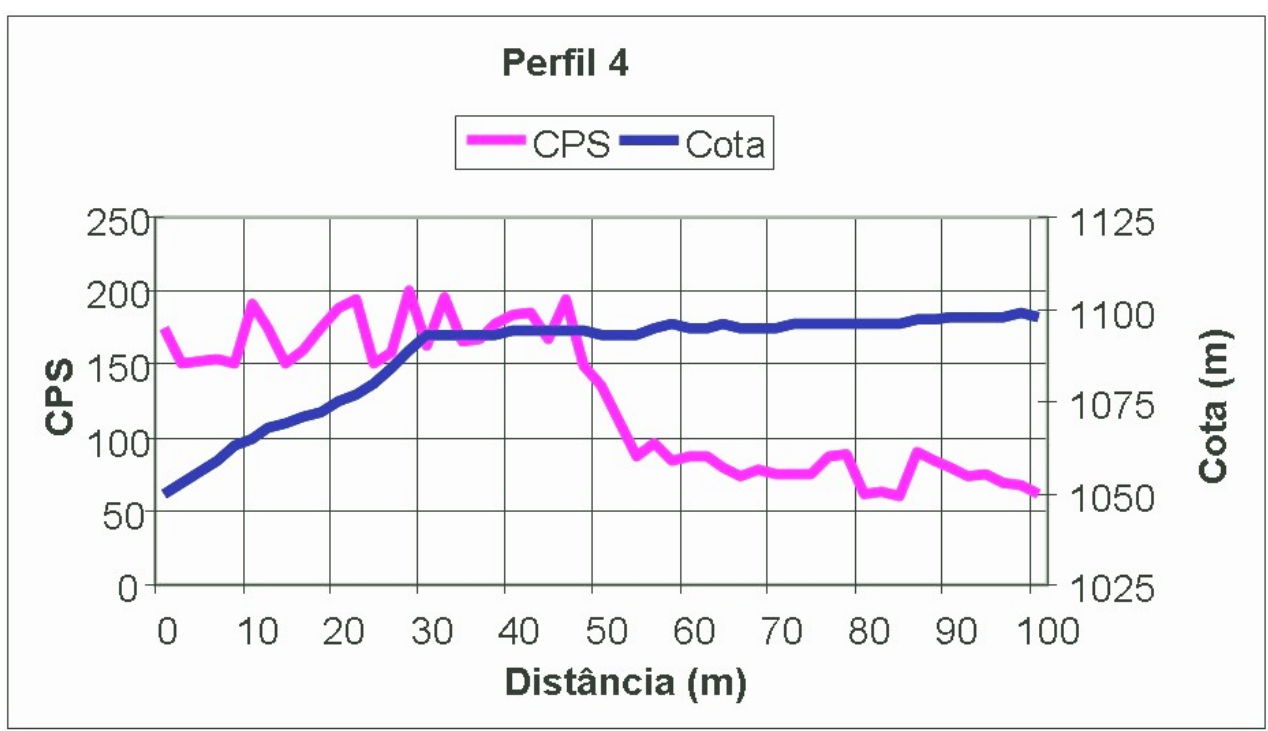

Figura 6 - Perfis centilométricos obtidos na região da figura 5: a) perfil 3; b) perfil 4. 


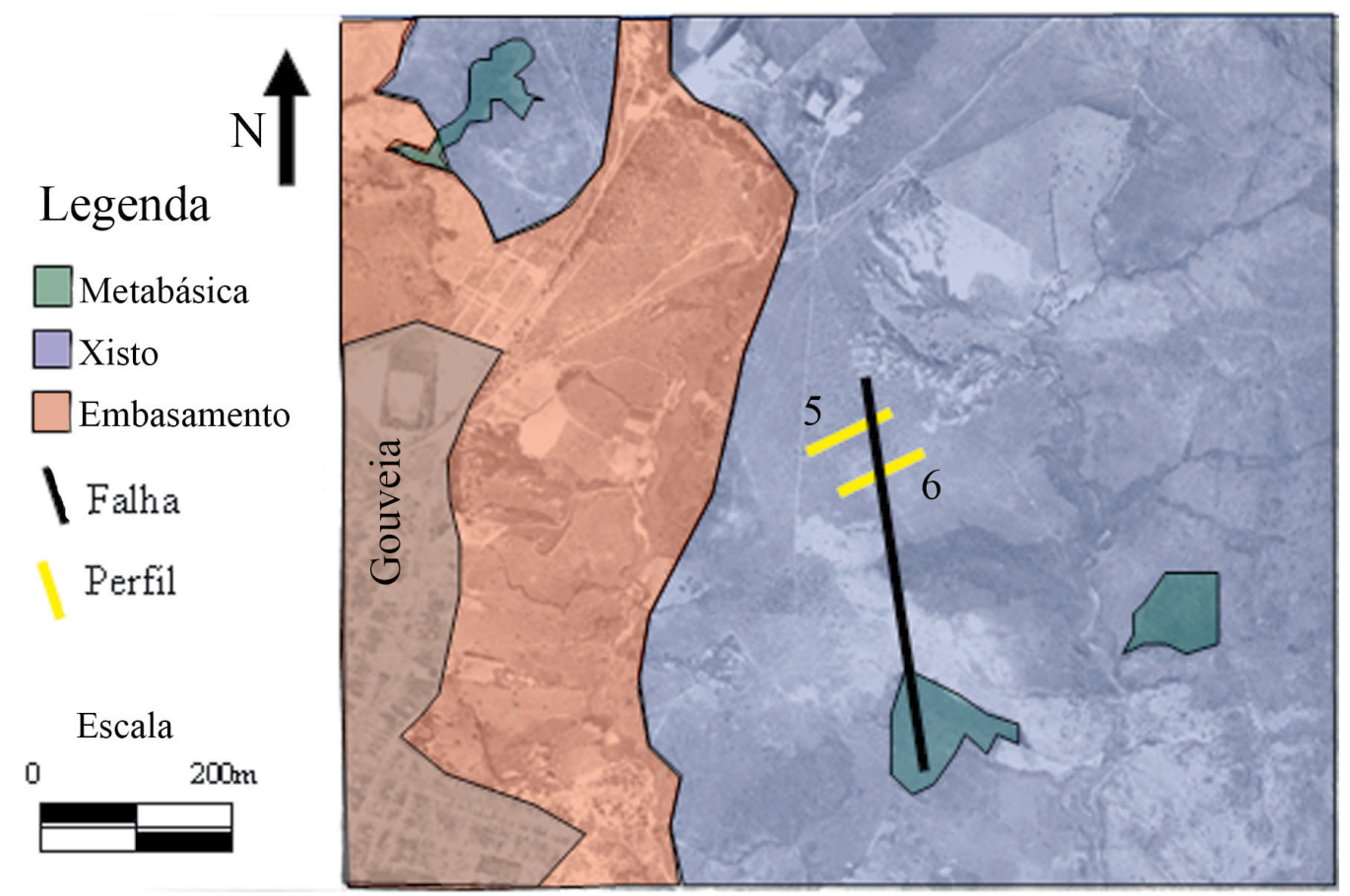

Figura 7 - Interpretação geológica de foto-aérea, com a localização dos perfis geofísicos 5 e 6, na região de Gouveia, $M G$.

devido à necessidade de caracterização geofísica de um falhamento de cunho regional no local. No afloramento, segundo Pena (2006), ocorre uma rocha bem semelhante a um quartzito róseo bem recristalizado (Figura 7). Uma lente de quartzito róseo que ocorre na Fm. Barão do Guaicuí, interpretada inicialmente como um cataclasito ou brecha de falha. Para tal caracterização, foram obtidos dois perfis cintilométricos paralelos entre si e espaçados em torno de $50 \mathrm{~m}$. Utilizou-se um espaçamento de amostragem de 2 metros ao longo da linha, e coleta de dados UTM e cota no ínicio, meio e final do perfil. As linhas de aquisição foram dimensionadas de modo que estas fôssem perpendiculares à estrutura detalhada em questão.

Analisando os dados cintilométricos, nota-se claramente um sinal mais alto nos locais de cota mais baixa (onde a rocha aflora), tanto para o Perfil 5 quanto para o Perfil 6. Embora alguns picos em torno de 125 CPS ocorram em ambos os Perfis, os valores encontrados foram relativamente baixos aos valores esperados para uma zona local de intensa remobilização fluída. Estes picos estariam, então, relacionados a falhamentos secundários ou enriquecimentos locais de minerais. Uma pequena zona de cisalhamento (não representável no mapa) é responsável pelo pico de CPS na metragem $90 \mathrm{~m}$ do Perfil 5. Observando-se os dados de CPS do Perfil 6 nota-se que provavelmente existem outras pequenas zonas de cisalhamento paralelas à esta que causam as mesmas variações nestes dados.

Os dados anteriores permitem inferir que a delgada camada de quartzito encontrada no local consiste no retrabalhamento do próprio xisto Barão de Guaicuí (um cataclasito ou brecha de falha). Esta intercalação foi interpretada como uma seqüência deposicional e intrínseca à Formação Barão do Guaicuí.

A terceira área, na qual se teve a necessidade de caracterização do material rochoso não-aflorante na área (Figura 9), está localizada próxima à grande lavra de quartzo leitoso no centro-sul da área mapeada.

Foram efetuadas duas séries de perfis cintilométricos e de georadar perpendiculares entre si (perfis no sentido N / S e E / W). O Perfil 8 intercepta o Perfil 7 aproximadamente na distância de $30 \mathrm{~m}$, enquanto o Perfil 7 intercepta o Perfil 8 em 25m. Para ambas as séries foram utilizadas amostragens de dados cintilométricos a cada 5 metros de investigação, com coleta de coordenadas UTM, e cota no ínicio, meio e final do perfil. O perfil Georadar 1 é paralelo ao Perfil 7 e o Perfil Georadar 2 é paralelo ao Perfil 8.

Ao se observar os perfis de cintilometria (Figura 10) nota-se que no perfil 7 os valores médios é de 215 CPS enquanto o Perfil 8 apresentou valores médios de 207 CPS.

Observa-se uma relativa constância dos valores de CPS para o Perfil 7, embora valores menores ocorram próximo à distância de $50 \mathrm{~m}$. Esta variação pode ser correlacionável com possíveis alterações da estrutura subsuperfícial da rocha, pois no radargrama do perfil Georadar 1 (Figura 11a) observa-se um refletor principal (refletor 1), conspícuo e de grande continuidade lateral que pôde ser individualizado e interpretado como o topo do embasamento não aflorante. Aproximadamente na distância de 30m inicia-se uma série de outros refletores menores que extendem-se, em alguns casos, até o final da seção. Principalmente devido a sua forma levemente lenticular, e aos valores de cintilometria, esta foi interpretada com um cavalgamento de possíveis lascas tectônicas do embasamento, apresentando algumas 
a)
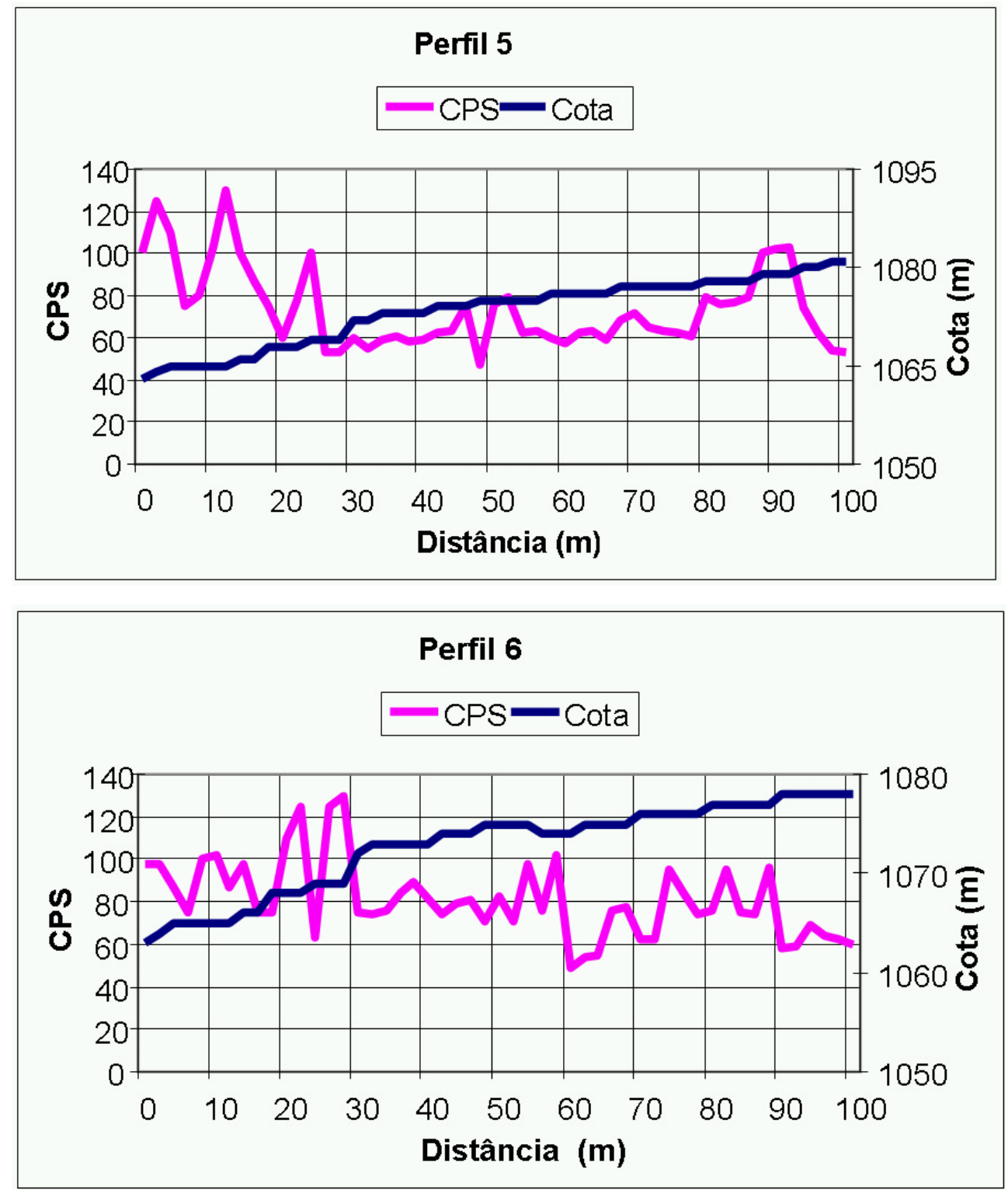

Figura 8-Perfis geofísicos a) perfil cintilométrico 5; b) perfil centilométrico 6.

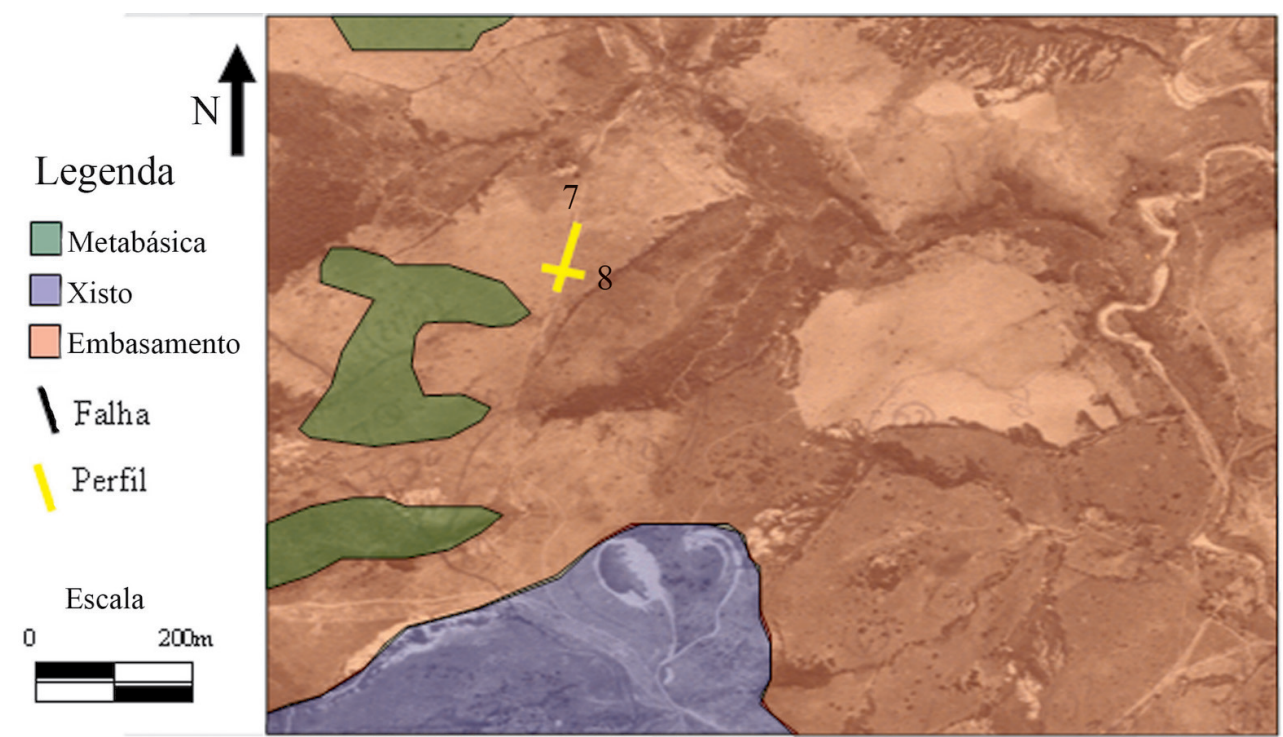

Figura 9 Interpretação geológica da foto-aérea, com a localização dos perfis geofísicos 7 e 8, região de Gouveia, MG. 
fraturas e, com isto uma variação lateral nos valores de cintilometria. Existe ainda outro refletor neste perfil de Georadar, Refletor 2, marcando uma possível zona mais intemperizada do embasamento. A figura 11b mostra a interpretação do radargrama da Figura 11a.

No Perfil cintilométrico 8 (figura 10b) pode-se notar uma cerca constância nos valores de CPS, apresentando valores menores na distância de $40 \mathrm{~m}$, sendo correlacionada a falhamento visualizado neste local no Perfil Georadar 2. Este dado corrobora com o sistema de fraturamento encontrado em ambos os perfis de Georadar.

Para o Perfil Georadar 2 (Figura 12), que intercepta o Perfil Georadar 1 em aproximadamente $30 \mathrm{~m}$, nota-se um conspíco refletor (refletor 1) na parte superficial à direita do radargrama denotando uma visível mudança de sinal e marcando a separação entre saprólito e corpo rochoso. Neste radargrama observam-se também alguns lineamentos interpretados como fraturas.

\section{VI - CONCLUSÕES}

Com base nos dados cintilométricos pôde-se determinar com precisão o contato entre o Embasamento e o xisto, como o observado na figura 5. Os perfis de cintilometria mostrarem claramente o ponto de contato entre as duas litologias, uma vez que esse contato não pôde ser bem delineado na foto-aérea e nem era bem visível no campo.

Em geral utilizou-se o padrão de respostas de valores cintilométricos encontrados na região, para auxiliar na definição dos contatos litológicos. Para o Complexo de Gouveia, a resposta associada ao embasamento (granito indeformado) gira em torno de 185 cintilações por segundo (CPS). Quando mais deformado, o sinal pode chegar a valores superiores a 230 CPS. Para a Formação Barão do Guaicuí os valores de cintilometria e obtidos são sempre menores quando comparados aos dados relacionados ao embasamento.
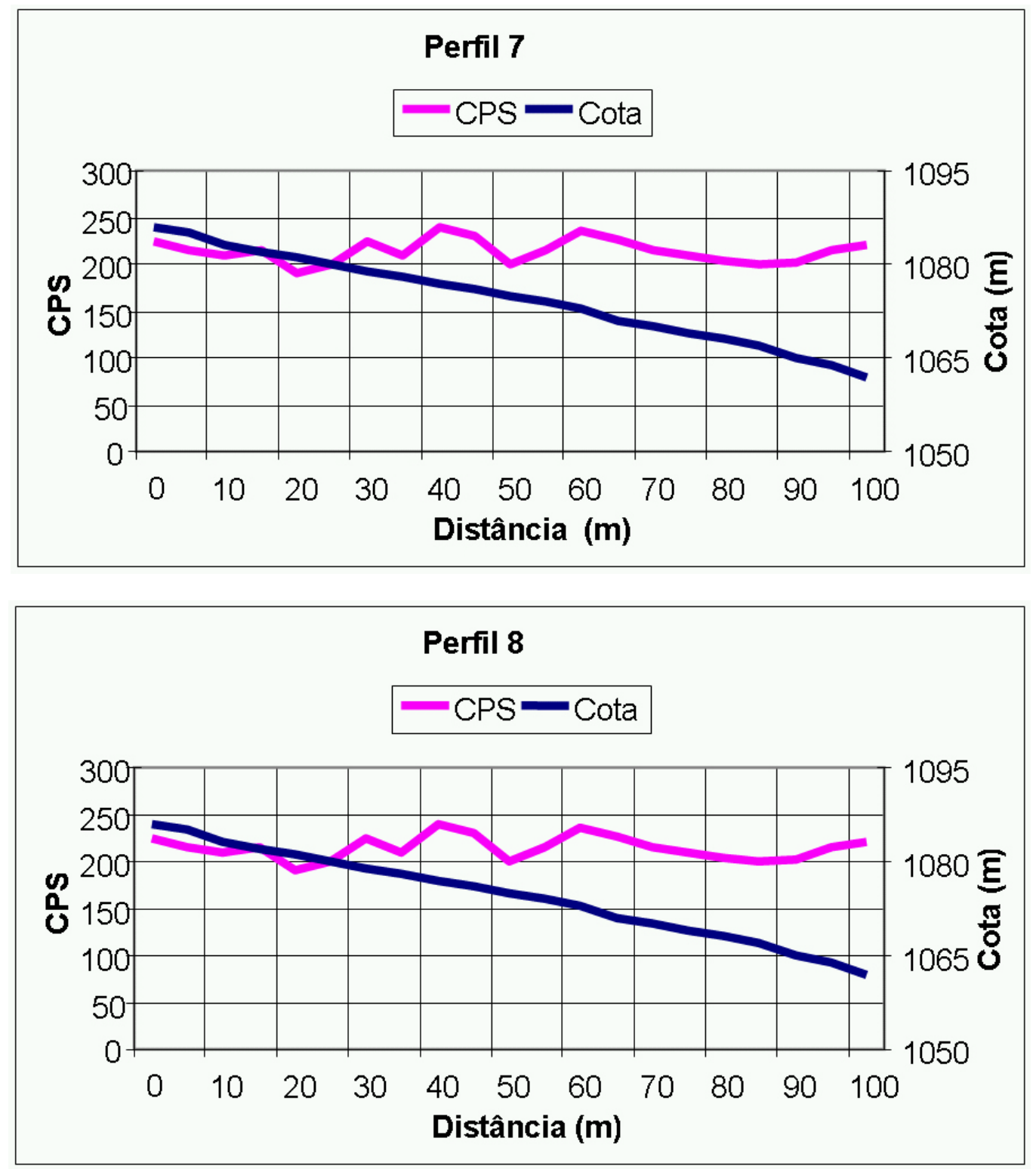

Figura 10 - Perfis cintilométricos obtidos na região da figura 9: a) perfil 7; b) perfil 8. 


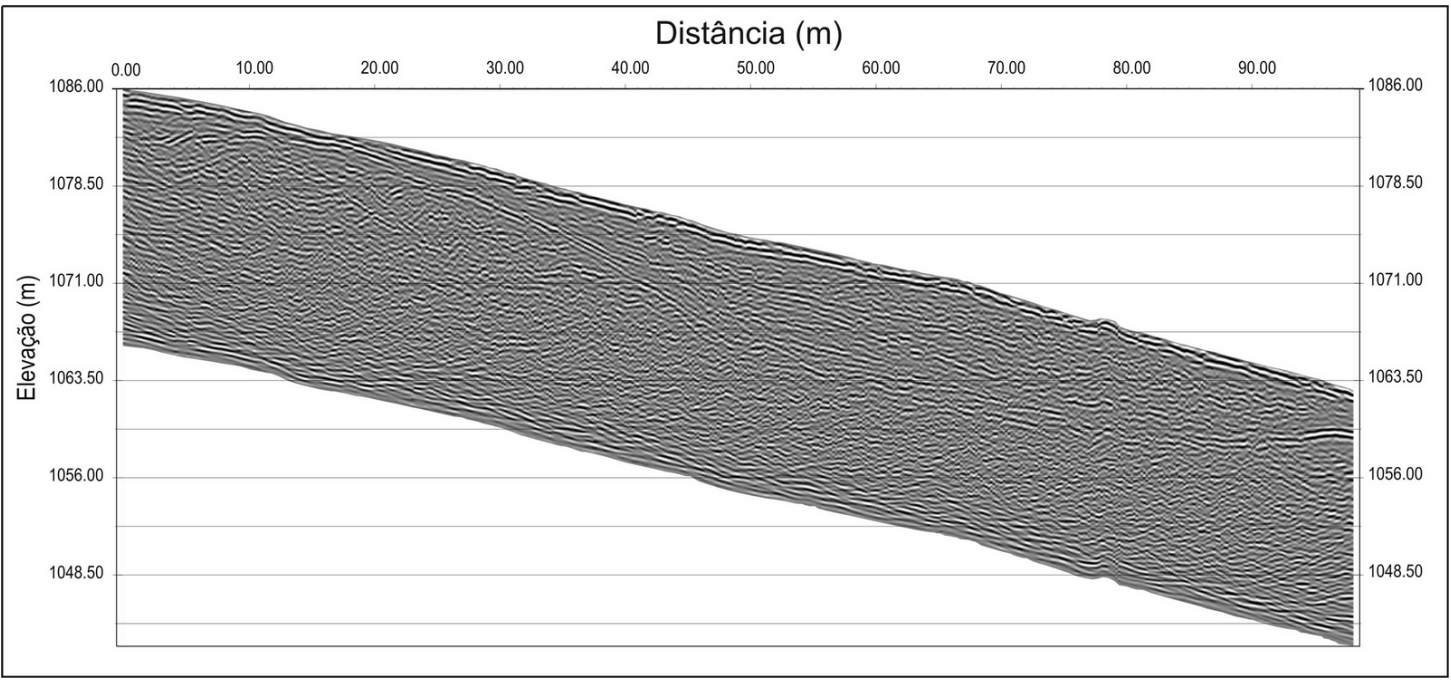

Figura 11 - Radargrama do perfil de Georadar 1, obtido com antenas de 100MHz; a) processado; b) intepretação do radargrama.

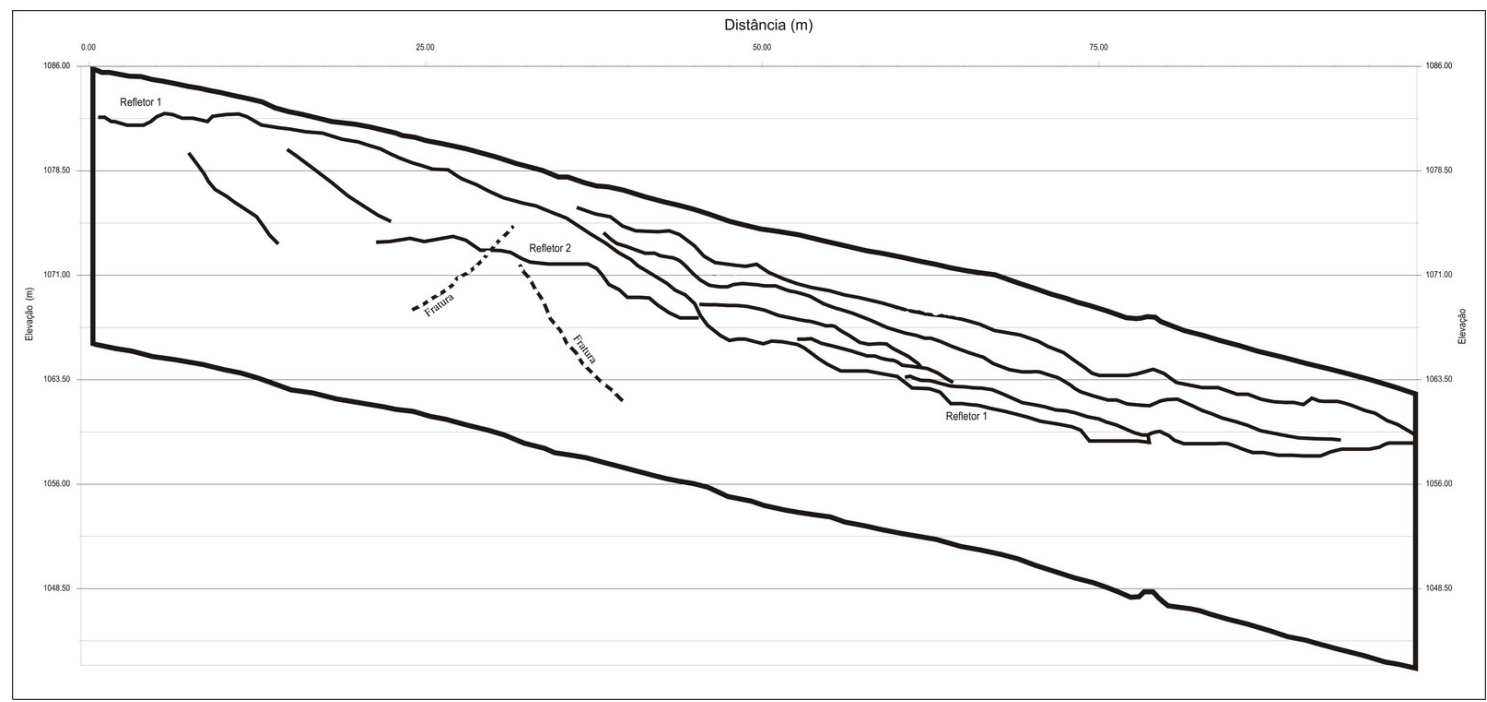

Figura 12 - Radargrama do perfil de Georadar 2, obtido com antenas de 100MHz; perpendicular ao perfil de georadar 1.

Os dados cintilométricos oscilam em torno de 80 CPS, esses valores médios de CPS foram considerados bases comparativas para outros perfis, Variações locais relacionadas a enriquecimentos de minerais devido à falhamentos, cisalhamentos, mantos intempéricos.

Em outro local, figura 9, estava-se em dúvida quanto à interpretação das feições observáveis na foto-aérea, variação na textura. Entretanto a associação de dados de cintilometria com os dados de georadar, permitiram caracterizar o identificar uma estrutura da subsuperfície, mostrando que se tratava de uma mesma litologia, apenas com a presença uma estrutura similar à uma lascas tectônicas. Esta feição foi bem caracterizada pela imagem de georadar.

Desse modo conclui-se que os métodos geofísicos mostraram-se eficientes no auxílio do mapeamento realizado, principalmente quando a ausência de afloramentos é uma constante. Através da cintilometria e do Georadar foi possível criar um critério geofísico para a individualização das litologias presentes na área.

\section{Agradecimentos}

Os autores Agradecem à Fapemig pelo apoio financeiro (CRA-1189-05), ao Departamento de Geologia, e aos revisores pelas sugestões e comentários.

\section{REFERÊNCIAS BIBLIOGRÁFICAS}

ALMEIDA-ABREU, P.A. (1989). Geologia das quadrículas Onça e Cuiabá (Gouveia-MG), região mediana-central da Serra do Espinhaço Meridional. Universidade Federal do Rio de Janeiro, Tese Mestrado, Rio de Janeiro, 90 pp.

ALMEIDA-ABREU, P.A., (1995). O Supergrupo Espinhaço da Serra do Espinhaço Meridional (Minas Gerais): O Rifte, a Bacia e o Orógeno. Geonomos 3 (1): 1-18;

ARANHA, P.R.A.; AUGUSTIN, C.H.R.R.; LÚCIO, P.S.; NEVES, F.A.P.S. (1998). Estudo das coberturas superficiais na região de Gouveia-MG, com o uso do GPR. In: XL Congresso Brasileiro de Geologia, 1998, Belo Horizonte, Anais do XL Congresso Brasileiro de Geologia, v. II, 1998. 387 p. 
ARANHA, P.R., AUGUSTIN, C.H.R.R., SOBREIRA, F.G. (2002) The use of GPR for characterizing underground weathered profiles in the sub-humid tropics. Journal of Applied Geophysics vol.49, n4, pp. 195-210.

BOTELHO, M.A.B.; XAVIER, J.; ARANHA, P.R.A. (1999). Estudo sobre a economicidade de jazidas de rochas ornamentais empredando o geo-radar (GPR). In: 6 Congresso Internacional da Sociedade Brasileira de Geofísica, 1999, Rio de Janeiro, Anais do 6 Congresso Internacional da Sociedade Brasileira de Geofísica, v. 1, 1999.

CARRINO, T.A., Souza Filho, C.R. \& Leite, E.P. (2007). Avaliação do uso de dados aerogeofísicos para mapeamento geológico e prospecção mineral em terrenos intemperizados: o exemplo de Serra Leste, província mineral de Carajás. Rev. Bras. Geof., vol.25, no.3, p.307-320.

CORDEIRO, J.S.; FERREIRA, A.F.; ARANHA, P.R.A.; COSTA, R.D. \& SILVA FILHO, J.A. (2007) Aplicação de gpr e cintilometria para a caracterização de descontinuidades estruturais e litológicas na porção leste da serra do cantagalo, são tomé das letras (mg). Geonomos, V15, n.2, p.21-31.

DAVIS, J.L. \& ANNAN, A.P. (1989). Applications of ground penetrating radar to mining, groundwater and geotechnical projects: Selected case histories. In: Worshop on Ground Probing Radar, 1988, Ontario: Geological Survey of Canada, paper 90-4, p.49-55.

DOSSIN, I.A. \& DOSSIN, T.M., (1995). Supergrupo Espinhaço: modelo de evolução geodinâmica. Geonomos 3 (1): 19-26

HARARI, Z. (1996). Ground Penetrating Radar (GPR) for imaging stratigraphic features and groundwater in sand dunes. Journal of applied Geophysics, 36: 43-52.

PENA, R.M. (2006). Mapeamento geológico e caracterização geofísica por cintilometria, magnetometria e georadar da região de Gouveia / MG. Monografia de Graduação, Departamento de Geologia, Instituto de Geociências - UFMG, Belo Horizonte, MG. 125p.

PORSANI J.L. \& RODRIGUES, A.R. (1995). O Método GPR aplicado à caracterização de reservatórios: Um exemplo na bacia potiguar - RN. In: Congresso Internacional da Sociedade Brasileira de Geofísica, 4, 1995, Rio de Janeiro. Resumos expandidos ..., Rio de Janeiro: SBGf, v.2, p.843-845

RODRIGUES, A.R. \& PORSANI, J.L. (1997). Diferentes litologias, diferentes situações, diferentes respostas. A utilização do método GPR como ferramenta de suporte à geologia. In: Congresso internacional da Sociedade Brasileira de Geofísica, 5, 1997, São Paulo. Resumos expandidos..., São Paulo: SBGf, v.1, p.540-543.

SOUZA Jr. \& PORSANI, J.L. (2001). Localização de fraturas em rochas graníticas, no município de Capão Bonito - SP, Brasil. In: 7th International Congresso of the Brazilian Geophysical Society, Resumos expandidos..., Salvador, BA, SBGf, CD.

RUY, A.C., SILVA, A.M., TOLEDO, C.L.B. \& SOUZA FILHO, C.R. (2006). Uso de dados aerogeofísicos de alta densidade para mapeamento geológico em terrenos altamente intemperizados: o estudo de caso da região de Cláudio, porção sul do Cráton São Francisco. Rev. Bras. Geof., Dez 2006, vol.24, no.4, p.535-546.

UHLEIN, A. (1991). Transição Craton - Faixa Araçuaí (Ciclo Brasiliano) no Estado de Minas Gerais. Aspectos estratigráficos e estruturais. Dissertação de doutoramento, Universidade de São Paulo, São Paulo, 259 p. 